\section{Regards sur l'économie allemande}

Bulletin économique du CIRAC

$84 \mid 2007$

Varia

\title{
Conseil politique
}

DAGGER Steffen, KAMBECK Michael (eds), Politikberatung und Lobbying in Brüssel / JENS Uwe, ROMAHN Hajo (eds), Glanz und Elend der Politikberatung

\section{(2) OpenEdition}

12 Journals

Édition électronique

URL : http://journals.openedition.org/rea/412

DOI : $10.4000 /$ rea. 412

ISBN : 978-2-8218-0864-5

ISSN : 1965-0787

Éditeur

CIRAC

Édition imprimée

Date de publication : 1 décembre 2007

ISSN : 1156-8992

\section{Référence électronique}

"Conseil politique », Regards sur l'économie allemande [En ligne], 84 | décembre 2007, document 1, mis en ligne le 03 juin 2008, consulté le 22 septembre 2020. URL : http://journals.openedition.org/rea/412 ; DOI : https://doi.org/10.4000/rea.412

Ce document a été généré automatiquement le 22 septembre 2020.

(c) CIRAC 


\section{Conseil politique}

DAGGER Steffen, KAMBECK Michael (eds), Politikberatung und Lobbying in Brüssel / JENS Uwe, ROMAHN Hajo (eds), Glanz und Elend der Politikberatung

\section{RÉFÉRENCE}

DAGGER Steffen, KAMBECK Michael (eds), Politikberatung und Lobbying in Brüssel, VS Verlag für Sozialwissenschaften, Wiesbaden, 2007, 272 p.

JENS Uwe, ROMAHN Hajo (eds), Glanz und Elend der Politikberatung, Metropolis-

Verlag, Marburg, 2005, 272 p.

1 La volée de bois vert que donne en cette fin d'année le Conseil des Sages au gouvernement de coalition pour sa politique en rupture non seulement avec les réformes structurelles de l'Agenda 2010, mais aussi avec les préconisations du Conseil, illustrent à merveille la difficile relation entre approche scientifique et pratique de la politique dont nous avions publié une analyse dans un précédent numéro (REA 78/06). L'ouvrage collectif publié sous la direction de JENS et ROMAHN, et intitulé « Heurs et malheurs du conseil politique ", en donne un précieux aperçu fondé sur de multiples approches. La problématique dépasse de loin le cadre national, comme le révèle un autre ouvrage (DAGGER et al.) décrivant, exemple à l'appui, les délicates relations entre lobbies allemands et bruxellois, comme entre instances de conseil et institutions communautaires. (ib) 